Article

\title{
Anchoring ZnO Nanoparticles in Nitrogen-Doped Graphene Sheets as a High-Performance Anode Material for Lithium-Ion Batteries
}

\author{
Guanghui Yuan ${ }^{1}$, Jiming Xiang ${ }^{1}$, Huafeng Jin ${ }^{1}$, Lizhou Wu ${ }^{1}$, Yanzi Jin ${ }^{1}$ and Yan Zhao ${ }^{2, *}$ \\ 1 School of Chemistry and Chemical Engineering, Ankang University, Ankang 725000, China; \\ chem_yuan@163.com (G.Y.); jimingxiang@aku.edu.cn (J.X.); hfjin5155@126.com (H.J.); \\ akxywlz@163.com (L.W.); streamlet2000@163.com (Y.J.) \\ 2 Synergy Innovation Institute of GDUT, Heyuan 517000, China \\ * Correspondence: zhaoyan_sii@163.com
}

Received: 21 November 2017; Accepted: 5 January 2018; Published: 10 January 2018

\begin{abstract}
A novel binary nanocomposite, $\mathrm{ZnO} /$ nitrogen-doped graphene $(\mathrm{ZnO} / \mathrm{NG})$, is synthesized via a facile solution method. In this prepared $\mathrm{ZnO} / \mathrm{NG}$ composite, highly-crystalline $\mathrm{ZnO}$ nanoparticles with a size of about $10 \mathrm{~nm}$ are anchored uniformly on the $\mathrm{N}$-doped graphene nanosheets. Electrochemical properties of the $\mathrm{ZnO} / \mathrm{NG}$ composite as anode materials are systematically investigated in lithium-ion batteries. Specifically, the $\mathrm{ZnO} / \mathrm{NG}$ composite can maintain the reversible specific discharge capacity at $870 \mathrm{mAh} \mathrm{g}^{-1}$ after 200 cycles at $100 \mathrm{~mA} \mathrm{~g}^{-1}$. Besides the enhanced electronic conductivity provided by interlaced $\mathrm{N}$-doped graphene nanosheets, the excellent lithium storage properties of the $\mathrm{ZnO} / \mathrm{NG}$ composite can be due to nanosized structure of $\mathrm{ZnO}$ particles, shortening the $\mathrm{Li}^{+}$diffusion distance, increasing reaction sites, and buffering the $\mathrm{ZnO}$ volume change during the charge/discharge process.
\end{abstract}

Keywords: anode material; graphene nanocomposite; lithium-ion battery; $\mathrm{ZnO} /$ nitrogen-doped; $\mathrm{ZnO}$ nanoparticles

\section{Introduction}

Lithium-ion batteries (LIBs) are one of the most promising modern electrochemical devices for energy storage, due to their high voltage, high energy density, and long lifespan [1-4]. Graphite has been widely used as the anode material due to its exhibiting stable performance in commercial LIBs [5]. Whereas the theoretical capacity of graphite is only $372 \mathrm{mAh} \mathrm{g}^{-1}$ and it cannot meet the increasing power demands [6]. To address these issues, remarkable efforts have been made to develop various promising candidates for anode materials to replace graphite, such as transition metal oxides $(\mathrm{MO}$, $\mathrm{M}=\mathrm{Mn}, \mathrm{Fe}, \mathrm{Co}, \mathrm{Ni}, \mathrm{Cu}, \mathrm{Zn}$, etc.) [7-14].

Among the above metal oxides, $\mathrm{ZnO}$ anode stands out as a potential alternative anode due to its high theoretical capacity $\left(978 \mathrm{mAh} \mathrm{g}^{-1}\right)$, low cost, ease to preparation, and chemical stability [15-17]. However, pure $\mathrm{ZnO}$ generally exhibits low reversible capacity and severe capacity fading, such a result is mainly caused by its large volume variation during the Li-ion insertion/extraction processes [16]. A lot of effort has therefore been devoted to conquer the above-mentioned shortcomings and a series of methods have been performed to improve properties of $\mathrm{ZnO}$ electrode. These methods include (i) preparing ordered $\mathrm{ZnO}$ nanostructured materials [18-21]; (ii) compositing $\mathrm{ZnO}$ with carbon materials [5,15-17]; (iii) doping with other metal oxides [22-24]. These techniques can improve conductivity, promote the lithiation/delithiation process, or buffer volume changes to mitigate the pulverization of the active particles. Among these methods, the remarkable and effective strategy to overcome the low conductivity is to composite $\mathrm{ZnO}$ with high electro-conducting material such 
as porous carbon in the form of carbon supporting [25]. Among various carbon materials, graphene has been recognized as very serviceable material because of its excellent high thermal conductivity, electrical conductivity, and high specific surface area [26]. Considerable efforts to achieve controllable graphene and $\mathrm{ZnO} /$ graphene composites have been extensively made by many different techniques, such as plasma synthesis [27], homogenizing dispersion method [28], stepwise heterocoagulation method [29], freeze drying method [30] and so on [31,32]. Although these composites demonstrated enhanced electrochemical performance, it is still not completely satisfactory. To meet this challenge, nitrogen-doped (N-doped) graphene can increase its conductivity by raising the Fermi level towards the conduction band compared with pure graphene [33]. Moreover, N-doped graphene (NG) can offer more active nucleation sites, which effectively prevent the aggregation of nanoparticles and strengthen the binding energy [34,35]. Therefore, compared to graphene, NG is more favorable for the composition of the nanosheets with metal oxides.

To the best of our knowledge, there are few studies on synthesizing $\mathrm{ZnO} / \mathrm{N}$-doped graphene composite. In this work, we report a facile and scalable method to synthesize nanostructured $\mathrm{ZnO} / \mathrm{N}$-doped graphene ( $\mathrm{ZnO} / \mathrm{NG}$ ) nanocomposite. The effect of $\mathrm{N}$-doped graphene on $\mathrm{ZnO}$ anode performance are systemically investigated in LIBs, in which the $\mathrm{ZnO} / \mathrm{NG}$ nanocomposite can exhibit superior cycling stability and rate capability.

\section{Results and Discussion}

The crystal structure of the obtained $\mathrm{ZnO} / \mathrm{NG}$ composite is firstly investigated by XRD. Figure 1a exhibits the XRD patterns of $\mathrm{ZnO}, \mathrm{N}$-doped grapheme, and the as-prepared $\mathrm{ZnO} / \mathrm{NG}$ composite. The main peaks of $\mathrm{ZnO} / \mathrm{NG}$ composite agree with the peaks of $\mathrm{ZnO}$, which can be indexed as $\mathrm{ZnO}$ with the lattice parameters of $\mathrm{a}=0.325, \mathrm{~b}=0.325$, and $\mathrm{c}=0.5207 \mathrm{~nm}$ (JCPDS No. 36-1451). In addition, the $\mathrm{ZnO} / \mathrm{NG}$ composite displays an obvious diffraction peak at around $26^{\circ}$, which is attributed to the (002) reflection of stacking layers of graphene. The average size of $\mathrm{ZnO}$ crystallite in $\mathrm{ZnO} / \mathrm{NG}$ composite is calculated to be $9.9 \mathrm{~nm}$ using the Debye Scherrer's formula. The XRD pattern of $\mathrm{ZnO} / \mathrm{NG}$ indicates that small $\mathrm{ZnO}$ nanoparticles are successfully deposited on the surface of $\mathrm{N}$-doped graphene sheets. The presence of $\mathrm{N}$-doped graphene has no significant effect on the formation of $\mathrm{ZnO}$ nanoparticles. The results can also be proved by the following TEM data. The successful deposition of $\mathrm{ZnO}$ nanoparticles on the surface of $\mathrm{N}$-doped graphene sheets can facilitate electron transportation and alleviate the volume expansion of $\mathrm{ZnO}$ during the discharge/charge cycling, resulting in a drastic improvement of the electrochemical performance, which can be proved by the following electrochemical measurements. To determine the percentage of $\mathrm{ZnO}$ in the prepared $\mathrm{ZnO} / \mathrm{NG}$ composite, thermo gravimetric (TG) measurement was carried out under an air atmosphere. As shown in Figure 1b, the TGA curve of $\mathrm{ZnO} / \mathrm{NG}$ has an obvious one-step weight loss from around $400{ }^{\circ} \mathrm{C}$. When the temperature reaches $700{ }^{\circ} \mathrm{C}$, the sample remains approximately unchanged. Comparing to the TGA curve of pristine $\mathrm{ZnO}$, the percentage of coating NG in $\mathrm{ZnO} / \mathrm{NG}$ composite is about $30.4 \mathrm{wt} \%$.
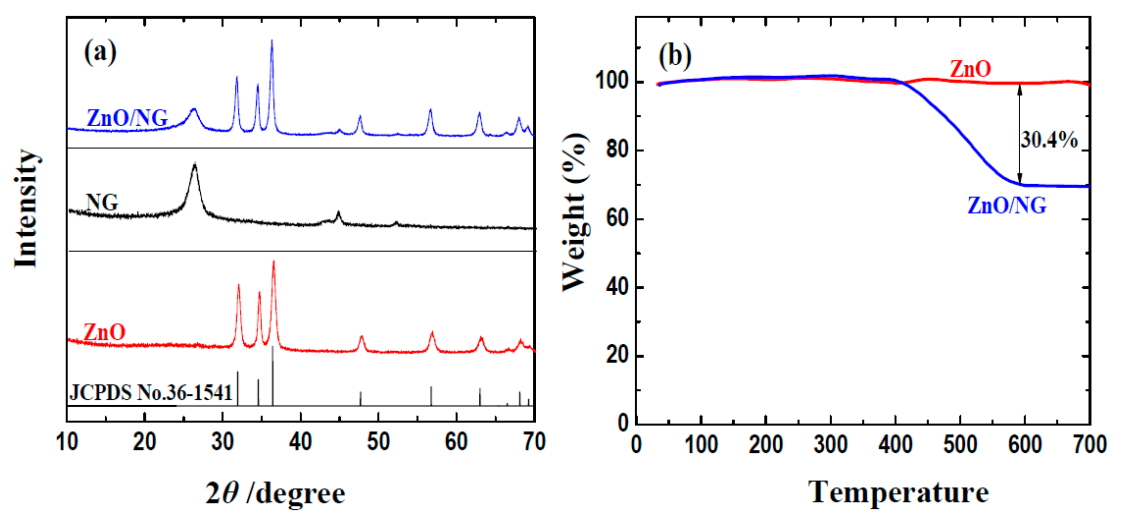

Figure 1. (a) XRD patterns; (b) thermogravimetric curves of $\mathrm{ZnO}$ and $\mathrm{ZnO} / \mathrm{NG}$ composite. 
To elucidate the valences of $\mathrm{C}, \mathrm{Zn}, \mathrm{N}$ elements and their bonds configuration in $\mathrm{ZnO} / \mathrm{NG}$ composite, XPS measurements are further investigated. Figure 2a displays the survey spectrums of $\mathrm{ZnO} / \mathrm{NG}$ and $\mathrm{ZnO} / \mathrm{G}$ composite. Four elements ( $\mathrm{Zn}, \mathrm{O}, \mathrm{C}$, and $\mathrm{N}$ ) can easily be detected through the characteristic peaks of $\mathrm{Zn} 2 \mathrm{p}, \mathrm{O} 1 \mathrm{~s}, \mathrm{C} 1 \mathrm{~s}$, and N1s in the survey spectrums of $\mathrm{ZnO} / \mathrm{NG}$ composite. In comparison, only the $\mathrm{Zn}, \mathrm{C}$, and $\mathrm{O}$ elements are identified through the survey spectrum of $\mathrm{ZnO} / \mathrm{G}$ composite. The result reveals that nitrogen doping existed in the $\mathrm{ZnO} / \mathrm{NG}$ composite synthesized by our simple solution method. Figure $2 b$ shows the high-resolution XPS spectra of Zn2p, which consists of two strong peaks at $1045.5 \mathrm{eV}$ and $1022.5 \mathrm{eV}$, identifying the $\mathrm{Zn} 2 \mathrm{p} 1 / 2$ and $\mathrm{Zn} 2 \mathrm{p} 3 / 2$ spin-orbit peaks of $\mathrm{ZnO}$, respectively. The $\mathrm{Zn} 2 \mathrm{p} 1 / 2-\mathrm{Zn} 2 \mathrm{p} 3 / 2$ energy separation is around $23.0 \mathrm{eV}$. The high-resolution scan of $\mathrm{C} 1 \mathrm{~s}$ is shown in Figure 2c. The strongest peak at $285.0 \mathrm{eV}$ corresponds to the graphite-like sp2 $\mathrm{C}(\mathrm{C}-\mathrm{C}$ and $\mathrm{C}=\mathrm{C}$ bonds), indicating that most $\mathrm{C}$ atoms in the $\mathrm{ZnO} / \mathrm{NG}$ composite are ranged in the conjugated honeycomb lattice. The peak located at $286.1 \mathrm{eV}$ is related to the C-N linkage, which is originated from the $\mathrm{N}$ atoms' incorporation of the $\mathrm{ZnO} / \mathrm{NG}$ composite. The weakest peak at $288.8 \mathrm{eV}$ reflects the $\mathrm{C}=\mathrm{O}$ linkage, which indicates a little residual oxygen existed in the $\mathrm{ZnO} / \mathrm{NG}$ composite. In addition, the special peak at $283.5 \mathrm{eV}$ in the $\mathrm{C} 1 \mathrm{~s}$ spectrum can be assigned to the $\mathrm{Zn}-\mathrm{O}-\mathrm{C}$ bond [36]. The N1s spectrum of the $\mathrm{ZnO} / \mathrm{NG}$ composite shown in Figure 2d can be attributable to the pyridinic $\mathrm{N}$, pyrrolic $\mathrm{N}$, and graphitic $\mathrm{N}$ atoms doped in graphene, according to the peaks at 398.3, 399.8 , and $401.7 \mathrm{eV}$, respectively [37,38]. The $\mathrm{N}$ atoms doped in graphene have excellent electron donor characteristics and good charge mobility in the graphene lattice, which can effectively improve carbon catalytic activity in electrochemical reactions [39]. Predicatively, the $\mathrm{ZnO} / \mathrm{NG}$ composite obtained in this work can enhance the electrochemical performance of anode material in lithium-ion batteries.
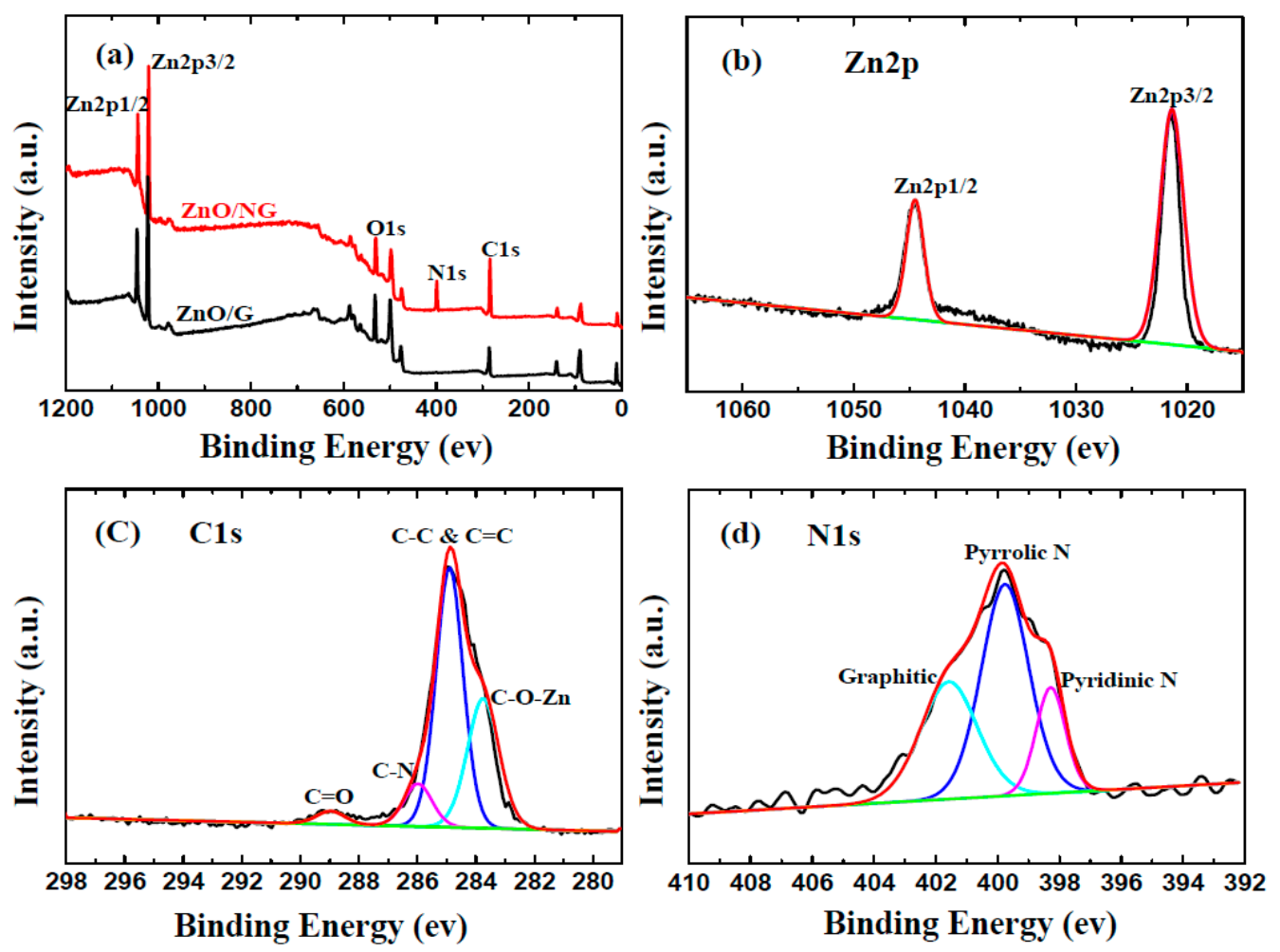

Figure 2. Survey XPS spectra (a) of ZnO/NG and ZnO/G composites; XPS spectra of (b) Zn2p, (c) C1s, and (d) N1s of ZnO/NG composite.

Figure 3 shows the scanning electron microscopy (SEM) and transmission electron microscopy (TEM) images of the as-prepared NG and ZnO/NG composite. The SEM image shows that small ZnO nanoparticles were well supported homogeneously on the curved $\mathrm{N}$-doped graphene surface, as seen in Figure 3a. To further investigate the distribution and size of $\mathrm{ZnO}$ particles in $\mathrm{ZnO} / \mathrm{NG}$ composite, 
the pristine NG and ZnO/NG composites are characterized by TEM. Figure 3b shows the TEM image of the synthesized $\mathrm{N}$-doped graphene. The stacking layers of $\mathrm{N}$-doped graphene show an obvious wrinkled surface, which is beneficial for $\mathrm{ZnO}$ nanoparticles to deposit and anchor on. As shown in the high-magnification TEM image of ZnO/NG composite (Figure 3c), small ZnO nanoparticles are barely obvious and agglomeration and the nanoparticles size are homogeneous. This result strongly indicates that the presence of nitrogen plays an essential role in the formation of homogeneous $\mathrm{ZnO}$. The $\mathrm{ZnO}$ nanoparticle diameter distribution obtained from TEM is determined to be about $10.0 \mathrm{~nm}$ (Figure 3d). The lattice fringe of an interplane distance is measured to be $0.26 \mathrm{~nm}$, which corresponds to the (002) plane of the $\mathrm{ZnO}$ crystals (insert in Figure 3d). The SEM and TEM images prove that the $\mathrm{ZnO} / \mathrm{NG}$ nanocomposite is successfully synthesized by our facile method. In the prepared $\mathrm{ZnO} / \mathrm{NG}$ nanocomposite, the $\mathrm{ZnO}$ particles with a size of about $10.0 \mathrm{~nm}$ are anchored uniformly on the wrinkled and twisted N-doped graphene sheets.

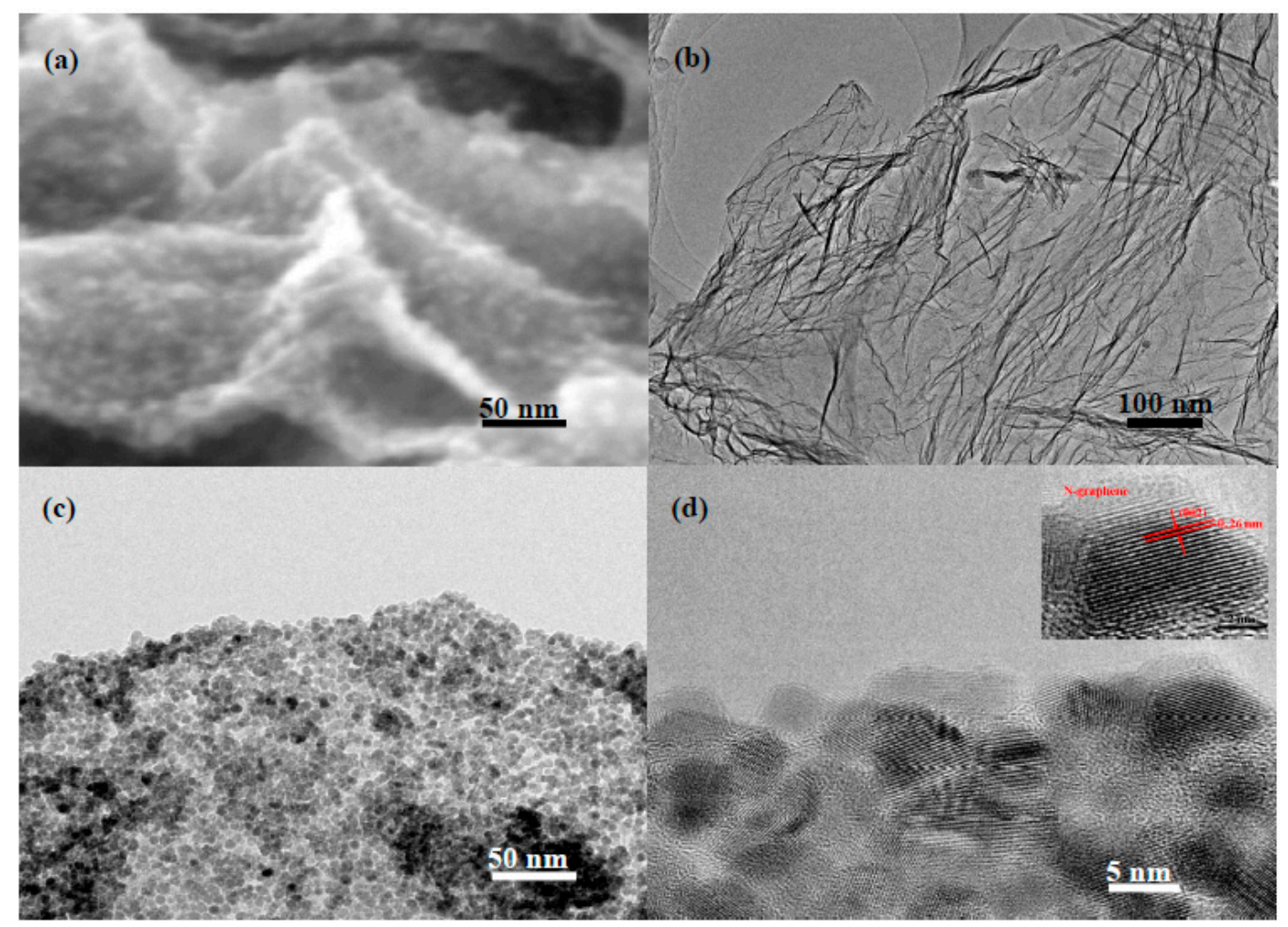

Figure 3. (a) SEM image of the ZnO/NG composite; TEM images of (b) NG and (c,d) ZnO/NG composite.

To examine the effect of $\mathrm{N}$-doped graphene, the electrochemical performance of $\mathrm{ZnO} / \mathrm{NG}$ nanocomposite in lithium-ion battery is systematically investigated. The cyclic voltammogarm (CV) profiles of $\mathrm{ZnO} / \mathrm{NG}$ electrode in the initial three cycles are exhibited in Figure $4 \mathrm{a}$ at $0.1 \mathrm{mV} \mathrm{s}^{-1}$ between 0-3.0 V. In the first cathodic scan, a strong reduction peak nearby $0.15 \mathrm{~V}$ can be observed in the $\mathrm{ZnO} / \mathrm{NG}$ composite electrode. It could be assigned to the reaction of $\mathrm{ZnO}$ with $\mathrm{Li}$ into $\mathrm{Zn}$ and $\mathrm{Li}_{2} \mathrm{O}$, the formation of Li-Zn alloy, and the solid electrolyte interphase (SEI) layer. In the subsequent second and third cathodic scans, the reduction peaks nearby 0.41 and $0.60 \mathrm{~V}$ demonstrate the reversibility of the lithiation process of $\mathrm{ZnO}$. The disappearance of the strong peak nearby $0.20 \mathrm{~V}$ indicates that the formation of the SEI layer is irreversible. The initial three anodic scans exhibit consistency in shape. The oxidation peaks nearby $0.38,0.54$, and $0.70 \mathrm{~V}$ indicate the multi-step decomposition of $\mathrm{Li}-\mathrm{Zn}$ alloy, while the nearby $1.34 \mathrm{~V}$ can be ascribed to the decomposition of $\mathrm{Li}_{2} \mathrm{O}$ and formation of $\mathrm{ZnO}$ with the reaction between $\mathrm{Li}_{2} \mathrm{O}$ and $\mathrm{Zn}[18,20]$. Overall, the CV curves show high reproducibility and consistency, indicating good reversibility of the $\mathrm{ZnO} / \mathrm{NG}$ electrode. The intensity of reduction and oxidation peaks grow weaker 
with the scans progress, which may be because of the incomplete conversion between $\mathrm{Zn}$ and $\mathrm{ZnO}$. Figure $4 \mathrm{~b}$ depicts the initial galvanostatic charge/discharge profiles of the ZnO/NG nanocomposite at a current density of $100 \mathrm{~mA} \mathrm{~g}^{-1}$. As shown in Figure $4 \mathrm{~b}$, the plateau voltages of the charge/discharge profiles are in good agreement with the peak voltages in CV profiles in Figure 4 a. The ZnO/NG nanocomposite delivers a large discharge capacity of $1894 \mathrm{mAh} \mathrm{g}^{-1}$ in the first cycle. The coulombic efficiency is only $56.5 \%$, which is mainly caused by the irreversible extra discharge capacity during the SEI layer formation. The long slope region observed in the initial discharge disappears in the following cycles. The $\mathrm{ZnO} / \mathrm{NG}$ nanocomposite delivers discharge capacities of 1148 and $968 \mathrm{mAh} \mathrm{g}^{-1}$ in the second and third cycles, respectively. The corresponding coulombic efficiencies have reached points of $79.9 \%$ and $87.4 \%$. After the first discharge process, the charge/discharge curves maintain a similar size and shape, indicating the $\mathrm{ZnO} / \mathrm{NG}$ nanocomposite keeps a relatively steady state during the lithiation/delithiation processes.
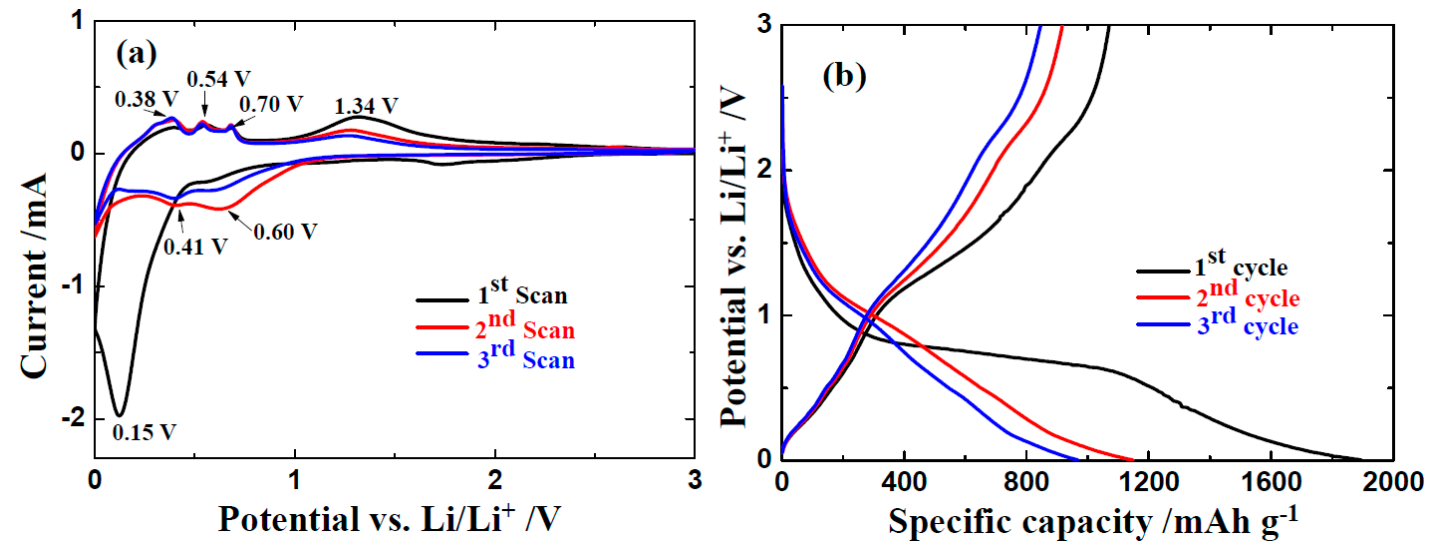

Figure 4. (a) $\mathrm{CV}$ curves of the $\mathrm{ZnO} / \mathrm{NG}$ composite electrode at a scan rate of $0.1 \mathrm{mV} \mathrm{s}{ }^{-1}$ and (b) discharge/charge profiles of $\mathrm{ZnO} / \mathrm{NG}$ anode at $100 \mathrm{~mA} \mathrm{~g}^{-1}$.

The rate performance and cycle ability are important aspects for the application of $\mathrm{ZnO} / \mathrm{NG}$ nanocomposite in lithium-ion batteries. Figure 5a shows the rate performances of the $\mathrm{ZnO} / \mathrm{NG}$ composite and its counterparts (pristine $\mathrm{ZnO}$ and $\mathrm{ZnO} / \mathrm{G}$ composite) at $100 \mathrm{~mA} \mathrm{~g}^{-1}$, respectively. The $\mathrm{ZnO} / \mathrm{G}$ composite is prepared by the same procedure as preparing $\mathrm{ZnO} / \mathrm{N}$-doped grapheme, just using graphene instead of $\mathrm{N}$-doped graphene. So the influence of different experiment methods on different electrochemical performances can be eliminated. As demonstrated in Figure 5a, the test current increases stepwise, and the rate performances of the $\mathrm{ZnO} / \mathrm{NG}$ and $\mathrm{ZnO} / \mathrm{G}$ electrodes have been significantly improved comparing to the pristine $\mathrm{ZnO}$ electrode. In detail, for the $\mathrm{ZnO} / \mathrm{NG}$ electrode, the reversible discharge capacities of 968,687, 567, 404, and $271 \mathrm{mAh} \mathrm{g}^{-1}$ are achieved at current rates of $100,200,400,800$, and $1600 \mathrm{~mA} \mathrm{~g}^{-1}$, respectively. The further return of the discharge rate to the initial $100 \mathrm{~mA} \mathrm{~g}^{-1}$ can recover the stable reversible discharge capacity of nearly $680 \mathrm{mAh} \mathrm{g}^{-1}$. For the $\mathrm{ZnO} / \mathrm{G}$ electrode at different current densities of 100, 200, 400, 800, and $1600 \mathrm{~mA} \mathrm{~g}^{-1}$, the reversible discharge capacities of each period are $849,521,404,282$, and $166 \mathrm{mAh}^{-1}$, respectively. While for the pristine $\mathrm{ZnO}$ electrode, the reversible discharge capacities at each current rate are 100 300 $\mathrm{mAh} \mathrm{g}^{-1}$ smaller than that of the $\mathrm{ZnO} / \mathrm{G}$ and $\mathrm{ZnO} / \mathrm{NG}$ electrodes. Long-term cycle abilities of the $\mathrm{ZnO}, \mathrm{ZnO} / \mathrm{G}$, and $\mathrm{ZnO} / \mathrm{NG}$ anodes at $100 \mathrm{~mA} \mathrm{~g}^{-1}$ are exhibited in Figure $5 \mathrm{~b}$. It can be easily seen that both the specific capacities and capacity retentions of the $\mathrm{ZnO} / \mathrm{G}$ and $\mathrm{ZnO} / \mathrm{NG}$ anodes are much better than that of the $\mathrm{ZnO}$ anode. During the three anodes, the $\mathrm{ZnO} / \mathrm{NG}$ anode could maintain the highest reversible specific discharge capacity of $870 \mathrm{mAh} \mathrm{g}^{-1}$ at $100 \mathrm{~mA} \mathrm{~g}^{-1}$ after 200 cycles. The $\mathrm{ZnO} / \mathrm{G}$ and pristine $\mathrm{ZnO}$ anodes could only deliver the reversible specific discharge capacity of 493 and $318 \mathrm{mAh} \mathrm{g}^{-1}$ at $100 \mathrm{~mA} \mathrm{~g}^{-1}$ after 200 cycles, respectively. The coulombic efficiencies of the three anodes are a little lower in the first several cycles, which could be inferred from the irreversible 
extra discharge capacity during the SEI layer formation. After 50 cycles, all the coulombic efficiencies of these anodes stabilize around $99 \%$, showing good capacity retention. Detailed observations from Figure 5 reveal that the reversibility and cycling stability of the $\mathrm{ZnO} / \mathrm{NG}$ and $\mathrm{ZnO} / \mathrm{G}$ anodes are better than that of the pristine $\mathrm{ZnO}$ anode. These enhanced electrochemical performances may be due to the positive effect of the graphene or $\mathrm{N}$-doped graphene additive, which are not only capable of providing a high electronic conductivity and short $\mathrm{Li}^{+}$diffusion distances, but also serving as a stable carrier for ultrafine $\mathrm{ZnO}$ particles anchored on it. Furthermore, the $\mathrm{ZnO} / \mathrm{NG}$ nanocomposite can deliver better electrochemical performances than $\mathrm{ZnO} / \mathrm{G}$ composite, which may be originated from the following two aspects. Firstly, the $\mathrm{N}$ atoms doped in graphene have excellent electron donor characteristics and good charge mobility in graphene lattice, which can effectively improve carbon catalytic activity in electrochemical reactions [33,34]. Secondly, the binding energy between ultrafine $\mathrm{ZnO}$ particles and $\mathrm{N}$-doped graphene nanosheets are improved due to the extra active sites provided by nitrogen doping.
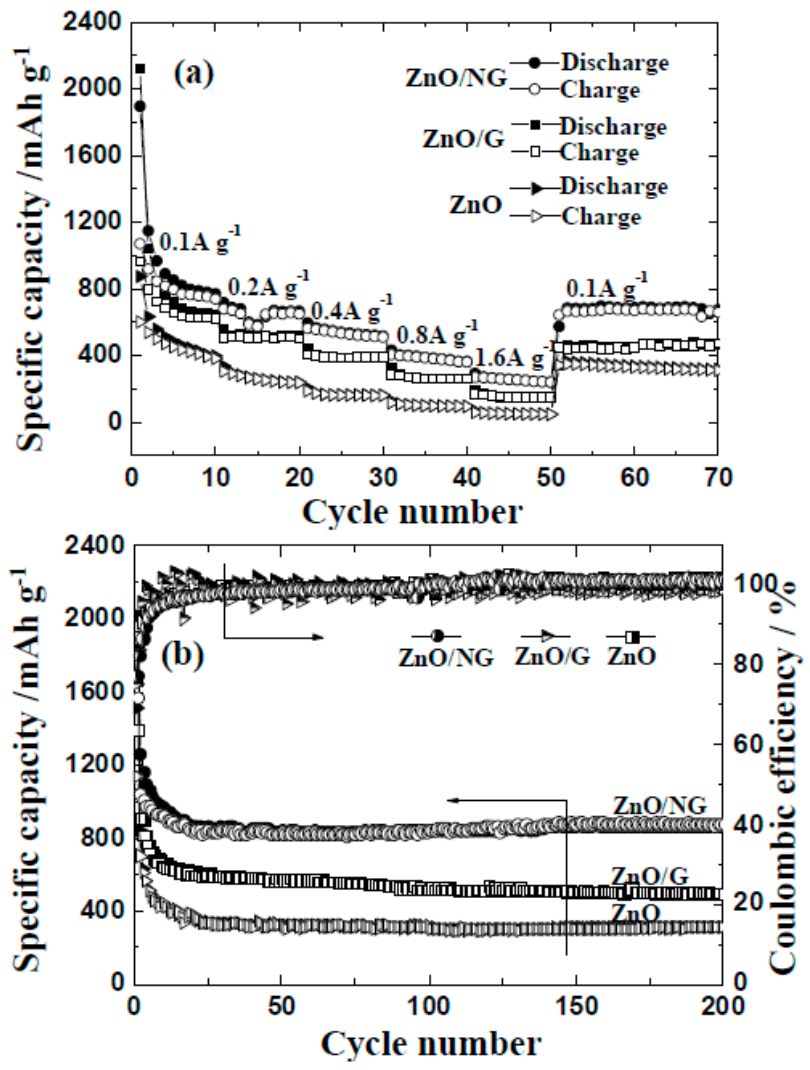

Figure 5. (a) Rate capabilities; (b) cycle abilities of $\mathrm{ZnO}, \mathrm{ZnO} / \mathrm{G}$, and $\mathrm{ZnO} / \mathrm{NG}$ anodes at $100 \mathrm{~mA} \mathrm{~g}^{-1}$.

Compared to previous work, the as-prepared $\mathrm{ZnO} / \mathrm{NG}$ composite exhibits more excellent electrochemical performances, as listed in Table 1 . The large initial discharge capacity delivered by $\mathrm{ZnO} / \mathrm{NG}$ composite is mainly caused by the irreversible extra discharge capacity during the SEI layer formation. The significantly improved cycle ability of $\mathrm{ZnO} / \mathrm{NG}$ composite benefits from the unique structure and the positive effect of the N-doped graphene. The $\mathrm{N}$-doped graphene nanosheets can not only improve the conductivity of the $\mathrm{ZnO} / \mathrm{NG}$ composite and provide more active electrochemical sites, but they can also alleviate the volume expansion of $\mathrm{ZnO}$ during the discharge/charge cycling. It is worth noting that $\mathrm{N}$-doped graphene itself can be used as anode material for lithium-ion batteries. During the discharge process of the $\mathrm{ZnO} / \mathrm{NG}$ composite, some $\mathrm{Li}$ ions can react with $\mathrm{ZnO}$ to form $\mathrm{Li}-\mathrm{Zn}$ alloy, other $\mathrm{Li}$ ions can intercalate into the stacking layers of $\mathrm{N}$-doped graphene in the meantime. Therefore, the $\mathrm{ZnO} / \mathrm{NG}$ composite shows better lithium storage capacities than $\mathrm{N}$-doped graphene material. 
Table 1. Comparison of electrochemical performances between the $\mathrm{N}$-doped graphene and $\mathrm{ZnO} / \mathrm{NG}$ composite.

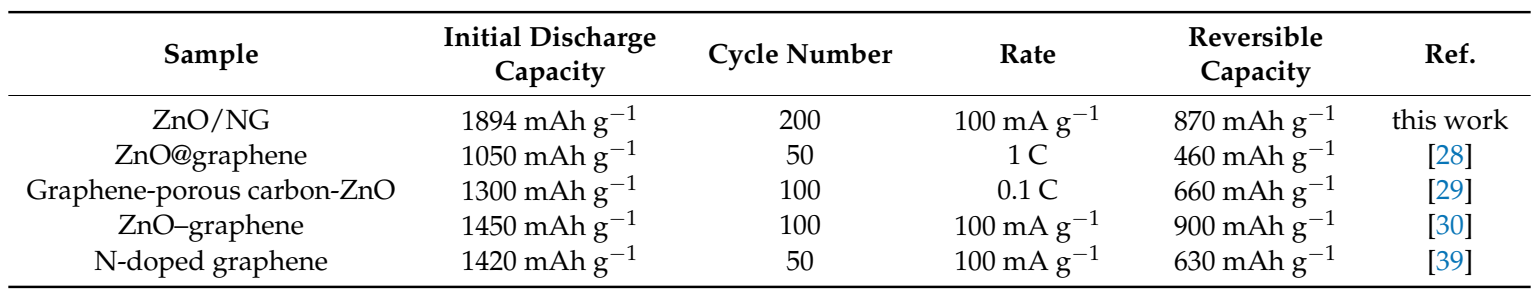

To confirm the positive effect of graphene or $\mathrm{N}$-doped graphene additives on the conductivity and charge transfer behavior in composites, electrochemical impedance spectroscopy (EIS) measurements were investigated on the $\mathrm{ZnO}, \mathrm{ZnO} / \mathrm{G}$, and $\mathrm{ZnO} / \mathrm{NG}$ electrodes. The EIS data for the three electrodes measured after the first cycle are shown in Figure 6a. All the impedance plots for the fully discharged states are composed of two parts, a semicircle in high-to-medium frequency and a straight line in low frequency. The semicircle is mainly attributed to the charge transfer impedance of the electrode. The straight line is mainly attributed to the Warburg impedance reflecting the solid-state diffusion of $\mathrm{Li}^{+}$into the bulk of the active materials [40]. It can be easily seen from Figure 6a that the charge transfer impedances of the $\mathrm{ZnO}, \mathrm{ZnO} / \mathrm{G}$, and $\mathrm{ZnO} / \mathrm{NG}$ electrodes are nearly 325, 130, and $90 \Omega$, respectively. Considering the formation of SEI is completed after first cycle, the impedances can be mainly attributed to the additive and the material structure. By adding graphene and $\mathrm{N}$-doped graphene, the charge transfer impedances of the $\mathrm{ZnO} / \mathrm{G}$ and $\mathrm{ZnO} / \mathrm{NG}$ electrodes decrease dramatically, indicating that the graphene or $\mathrm{N}$-doped graphene additive plays a significant role in improving the conductivity. The $\mathrm{ZnO} / \mathrm{NG}$ electrodes exhibit the smallest charge transfer impedance. The results could be due to the changes in the material conductivity and morphology introduced by N-doped graphene sheets [35]. The N-doped graphene can enhance the charge transfer conditions by providing an effective electron conduction path and shortening the $\mathrm{Li}^{+}$diffusion distance within the nanosized $\mathrm{ZnO}$ particles anchored evenly on the $\mathrm{N}$-doped graphene sheets. In addition, the EIS data of the $\mathrm{ZnO} / \mathrm{NG}$ electrode at different stages are shown in Figure $6 \mathrm{~b}$. The diameter of semicircles in the high-to-medium frequency region reduce gradually as the test proceeds, indicating the decrease of the charge transfer impedances. The charge transfer impedance of the new $\mathrm{ZnO} / \mathrm{NG}$ electrode is as high as about $170 \Omega$, which is mainly because the effective electron conduction paths and SEI layer are not formed in fresh electrode. Low and stable charge transfer impedances can be realized for the $\mathrm{ZnO} / \mathrm{NG}$ electrode during repeated discharge/charge cycles, which is about $90 \Omega$ and $80 \Omega$ after 1st cycle and 200th cycle, respectively. This phenomenon indicates that the special structure of the $\mathrm{ZnO} / \mathrm{NG}$ composite has beautiful rigidity and stability to endure the repeated lithium insertion/extraction processes.
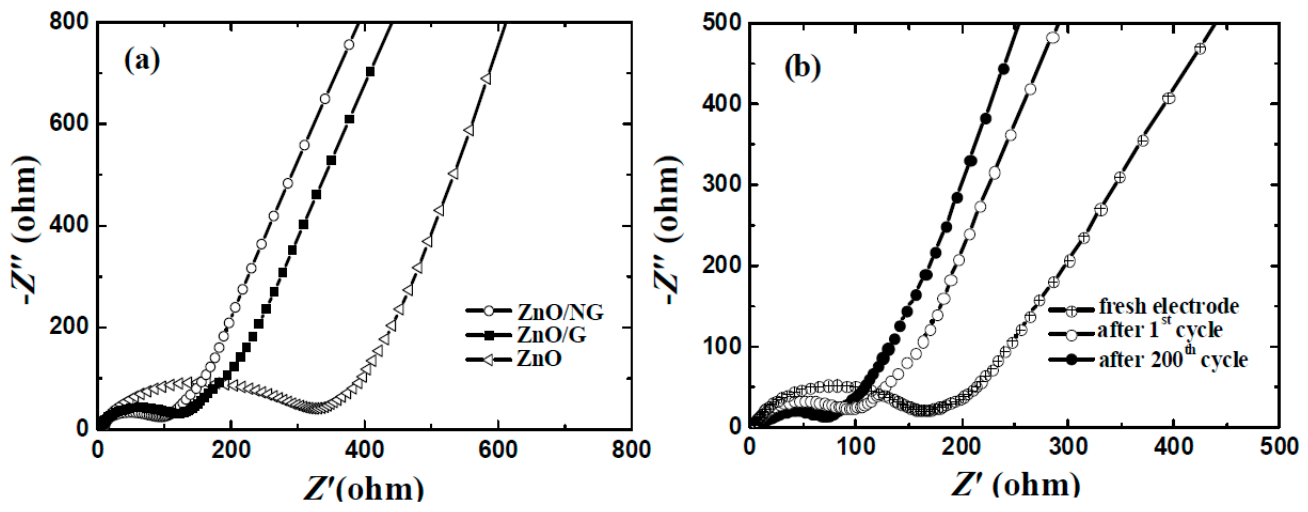

Figure 6. Nyquist plots of (a) $\mathrm{ZnO}, \mathrm{ZnO} / \mathrm{G}$ and $\mathrm{ZnO} / \mathrm{NG}$ electrodes after first discharge/charge cycle; and (b) $\mathrm{ZnO} / \mathrm{NG}$ electrode at different stages with the frequency region of $100 \mathrm{kHz}$ to $0.01 \mathrm{~Hz}$. 


\section{Materials and Methods}

Synthesis of nitrogen-doped graphene (NG): Firstly, graphene oxide (GO) was synthesized from natural flake graphite by a modified Hummers' method [41]. Subsequently, $0.060 \mathrm{~g}$ GO was dispersed into $100 \mathrm{~mL}$ ethanol. After ultrasonication for $2 \mathrm{~h}, 12 \mathrm{~mL}$ hydrazine hydrate and $8 \mathrm{~mL}$ of ammonia (25\%) were added into the suspension in order. The mixture was stirred vigorously for $15 \mathrm{~min}$ and then sealed into three $50 \mathrm{~mL}$ teflon-lined stainless steel autoclaves at $180{ }^{\circ} \mathrm{C}$ for $3 \mathrm{~h}$. The black powder in autoclaves was collected and washed by ethanol and distilled water and then dried in a vacuum oven at $80{ }^{\circ} \mathrm{C}$ overnight to obtain the NG product.

Synthesis of $\mathrm{ZnO} / \mathrm{NG}$ composite: Firstly, $0.720 \mathrm{~g}$ Zinc acetate $\left(\mathrm{Zn}\left(\mathrm{CH}_{3} \mathrm{COO}\right)_{2}\right)$ and $0.020 \mathrm{~g}$ NG were dispersed in $50 \mathrm{~mL}$ ethanol to form a homogeneous solution. A measure of $0.190 \mathrm{~g}$ lithium hydroxide $(\mathrm{LiOH})$ was dissolved in another $50 \mathrm{~mL}$ ethanol solution. Both solutions were stirred for $2 \mathrm{~h}$ using a magnetic stirrer. Subsequently, the $\mathrm{LiOH}$ solution was added dropwise to the $\mathrm{Zn}\left(\mathrm{CH}_{3} \mathrm{COO}\right)_{2}$ solution under constant vigorous stirring. After stirring for $24 \mathrm{~h}$ at room temperature, a homogenously dispersed black suspension was obtained. The black powders were separated via filtration and washed thoroughly by deionized water and ethanol. Finally, the black ZnO/NG composite was obtained followed by freeze-drying in vacuum freeze drier and grinding in agate mortar. For comparison, a $\mathrm{ZnO} / \mathrm{G}$ sample with addition of graphene and a $\mathrm{ZnO}$ sample without any addition were prepared as well by the same procedure. The preparation of the $\mathrm{ZnO} / \mathrm{NG}$ composite is illustrated in Figure 7.

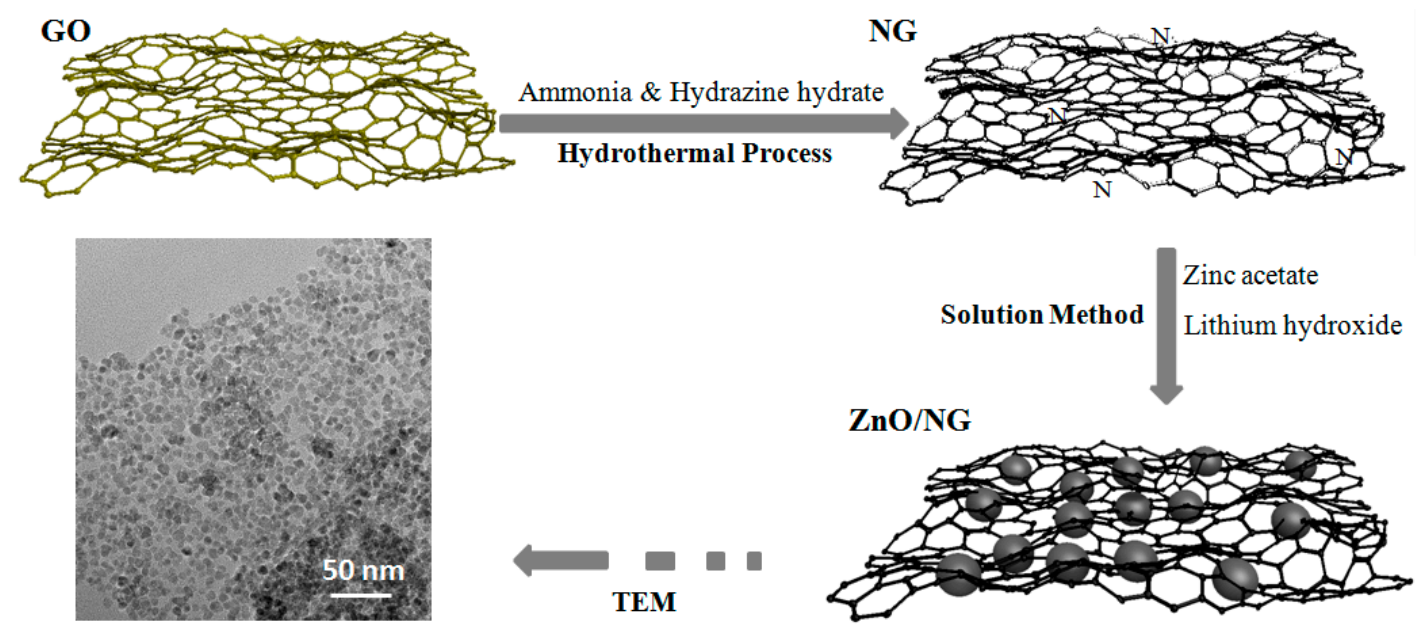

Figure 7. The preparation of the $\mathrm{ZnO} / \mathrm{NG}$ composite.

Powder X-ray diffraction (XRD, SmartLab, Rigaku Corporation, Tokyo, Japan) patterns of the samples were detected using $\mathrm{Cu} \mathrm{K} \alpha$ radiation $(\lambda=0.15418 \mathrm{~nm})$ at $0.02^{\circ} \mathrm{s}^{-1}$ in the $2 \theta$ range of $10^{\circ}-70^{\circ}$. Scanning electron microscopy (SEM) and transmission electron microscopy (TEM) images were obtained on a Quanta 400 ESEM-FEG instrument (FEI Corporation, Hillsboro, OR, USA) and a JEM-2100F instrument (JEOL Corporation, Akishima, Tokyo, Japan), respectively. X-ray photoelectron spectroscopy (XPS, PHI 5400 electron spectrometer) was performed using unmonochromated Mg $\mathrm{K} \alpha$ radiation $(\mathrm{h} v=1253.6 \mathrm{eV}$ ) as the excitation source. $\mathrm{NG}$ content in $\mathrm{ZnO} / \mathrm{NG}$ composite was estimated by thermogravimetric analysis (TGA, SDT Q600, TA Instruments, New Castle, DE, USA) in the temperature range of $30-700{ }^{\circ} \mathrm{C}\left(10{ }^{\circ} \mathrm{C} / \mathrm{min}\right)$ under air atmosphere.

The testing $\mathrm{ZnO} / \mathrm{NG}, \mathrm{ZnO} / \mathrm{G}$, and $\mathrm{ZnO}$ electrodes were prepared by mixing $80 \mathrm{wt} \%$ as-prepared active materials, $10 \mathrm{wt} \%$ polyvinylidene fluoride (PVDF, Sigma-Aldrich Corporation, Milwaukee, WI, USA), and $10 \mathrm{wt} \%$ acetylene black in N-methylpyrrolidone (NMP, Sigma-Aldrich Corporation, Milwaukee, WI, USA), and 10 wt \% acetylene black in) solvent to form homogeneous slurries. The mixture slurries were coated onto nickel foams measuring $10 \mathrm{~mm}$ in diameter and then dried in a vacuum oven at $120{ }^{\circ} \mathrm{C}$ for $10 \mathrm{~h}$. In order to acquire preferable contact between active materials 
and nickel foams, these testing electrodes were pressed at $15 \mathrm{MPa}$ for several minutes. The loading density of active material in each electrode was about $2 \mathrm{mg} \mathrm{cm}^{-2}$. For testing the electrochemical performances of the testing electrodes, the $\mathrm{ZnO} / \mathrm{NG} / / \mathrm{Li}$ batteries were assembled in coin-type (CR2025) cells in a glove box filled with argon, using pure lithium foil electrodes as the counter electrodes. The electrolyte was a mixed solvent of diethylene carbonate, dimethyl carbonate, and ethylene carbonate (1:1:1) containing of $1 \mathrm{M} \mathrm{LiPF}_{6}$, and the separator was microporous polypropylene membrane (Celgard 2400). The testing $\mathrm{ZnO} / \mathrm{G}$ and $\mathrm{ZnO}$ electrodes were prepared in the same way as the counterparts.

The galvanostatic charge and discharge tests were carried out on a program-control battery system (Wuhan LAND Electronic Co., Ltd., Wuhan, China). Cyclic voltammetry (CV) tests were performed on a electrochemical workstation (CHI 600E) at $0.1 \mathrm{mV} \mathrm{s}^{-1}$ in $0-3.0 \mathrm{~V}$. Electrochemical impedance spectroscopy (EIS) properties were measured in the frequency range of $0.01 \mathrm{~Hz}-100 \mathrm{kHz}$ using the same CHI 600E electrochemical workstation.

\section{Conclusions}

A novel $\mathrm{ZnO} /$ nitrogen-doped graphene $(\mathrm{ZnO} / \mathrm{NG}$ ) nanocomposite was synthesized via a facile solution method. In the prepared $\mathrm{ZnO} / \mathrm{NG}$ nanocomposite, the $\mathrm{ZnO}$ particles with size of about $10.0 \mathrm{~nm}$ were anchored uniformly on the wrinkled and twisted $\mathrm{N}$-doped graphene sheets. When used as anode materials, the $\mathrm{ZnO} / \mathrm{NG}$ nanocomposite exhibited much better electrochemical abilities compared to pristine $\mathrm{ZnO}$ and the $\mathrm{ZnO} /$ graphene $(\mathrm{ZnO} / \mathrm{G})$ nanocomposite. The resulting $\mathrm{ZnO} / \mathrm{NG}$ nanocomposite can maintain a reversible specific discharge capacity at $870 \mathrm{mAh} \mathrm{g}^{-1}$ after 200 cycles at $100 \mathrm{~mA} \mathrm{~g}^{-1}$. The enhanced electrochemical performances of the $\mathrm{ZnO} / \mathrm{NG}$ nanocomposite can be attributed to the $\mathrm{N}$-doped graphene additive and the unique structure of the composite. The cross-linked N-doped graphene nanosheets in the $\mathrm{ZnO} / \mathrm{NG}$ nanocomposite have outstandingly improved conductivity and high surface areas, which facilitate electron transportation and provide plenty of active sites for lithium ions, resulting in a drastic improvement of the rate performance. The ultrafine $\mathrm{ZnO}$ particles anchored evenly on $\mathrm{N}$-doped graphene nanosheets can not only enlarge the electrolyte/ZnO contact area, but also alleviate the volume expansion of $\mathrm{ZnO}$ during the discharge/charge cycling, resulting in an extreme enhancement of the cycle stability.

Acknowledgments: This work was supported by the Natural Science Fund of Education Department of Shaanxi Provincial Government (grant number 16JK1018); Natural Science Fund and Subject Merging Fund of Ankang University for high-level talents (Grant No. 2016AYQDZR05 and 2017AYJC01).

Author Contributions: Yan Zhao and Guanghui Yuan conceived and designed the experiments. Guanghui Yuan and Jiming Xiang carried out the experiments. Huafeng Jin and Lizhou Wu analyzed the data. Yanzi Jin and Guanghui Yuan contributed in the drafting and revision of the manuscript. Yan Zhao and Guanghui Yuan supervised the work and finalized the manuscript. All authors read and approved the final manuscript.

Conflicts of Interest: The authors declare no conflict of interest.

\section{References}

1. Lu, J.; Chen, Z.; Ma, Z.; Pan, F.; Curtiss, L.A.; Amine, K. The role of nanotechnology in the development of battery materials for electric vehicles. Nat. Nanotechnol. 2016, 11, 1031-1038. [CrossRef] [PubMed]

2. Goriparti, S.; Miele, E.; De Angelis, F.; Di Fabrizio, E.; Zaccaria, R.P.; Capiglia, C. Review on recent progress of nanostructured anode materials for Li-ion batteries. J. Power Sources 2014, 257, 421-443. [CrossRef]

3. Hy, S.; Liu, H.; Zhang, M.; Qian, D.; Hwang, B.J.; Meng, Y.S. Performance and design considerations for lithium excess layered oxide positive electrode materials for lithium-ion batteries. Energy Environ. Sci. 2016, 9, 1931-1954. [CrossRef]

4. Prabakar, S.R.; Han, S.C.; Jeong, J.; Sohn, K.S.; Pyo, M. CoSn $(\mathrm{OH})_{6}$ hybridized with anionic and cationic graphenes as a new high-capacity anode for lithium-ion batteries. Mater. Des. 2017, 118, 294-303. [CrossRef] 
5. Abbas, S.M.; Hussain, S.T.; Ali, S.; Ahmad, N.; Ali, N.; Abbas, S. Structure and electrochemical performance of $\mathrm{ZnO} / \mathrm{CNT}$ composite as anode material for lithium-ion batteries. J. Mater. Sci. 2013, 48, 5429-5436. [CrossRef]

6. Kim, T.; Jo, C.; Lim, W.G.; Lee, J.; Lee, J.; Lee, K.H. Facile conversion of activated carbon to battery anode material using microwave graphitization. Carbon 2016, 104, 106-111. [CrossRef]

7. Wang, J.G.; Yang, Y.; Huang, Z.H.; Kang, F. MnO-carbon hybrid nanofiber composites as superior anode materials for lithium-ion batteries. Electrochim. Acta 2016, 170, 164-170. [CrossRef]

8. Zhang, Y.G.; Li, Y.; Li, H.P.; Zhao, Y.; Yin, F.X.; Bakenov, Z. Electrochemical performance of carbon-encapsulated $\mathrm{Fe}_{3} \mathrm{O}_{4}$ nanoparticles in lithium-ion batteries: Morphology and particle size effects. Electrochim. Acta 2016, 216, 475-483. [CrossRef]

9. Li, G.; Wang, Y.; Yang, L.; Ma, W.; Wang, M. In situ synthesis of $\mathrm{ZnMn}_{2} \mathrm{O}_{4}-\mathrm{ZnO}-\mathrm{C}$ and $\mathrm{ZnMn}_{2} \mathrm{O}_{4}-\mathrm{C}$ nanohybrids as high performance lithium-ion battery anodes. Eur. J. Inorg. Chem. 2014, 5, 845-851. [CrossRef]

10. Zhang, B.; Hao, S.; Xiao, D.; Wu, J.; Huang, Y. Templated formation of porous $\mathrm{Mn}_{2} \mathrm{O}_{3}$ octahedra from Mn-MIL-100 for lithium-ion battery anode materials. Mater. Des. 2016, 98, 319-323. [CrossRef]

11. Yan, C.; Chen, G.; Zhou, X.; Sun, J.; Lv, C. Template-based engineering of carbon-doped $\mathrm{Co}_{3} \mathrm{O}_{4}$ hollow nanofibers as anode materials for lithium-ion batteries. Adv. Funct. Mater. 2016, 26, 1428-1436. [CrossRef]

12. Ma, Y.; Zhang, C.; Ji, G.; Lee, J.Y. Nitrogen-doped carbon-encapsulation of $\mathrm{Fe}_{3} \mathrm{O}_{4}$ for increased reversibility in $\mathrm{Li}^{+}$storage by the conversion reaction. J. Mater. Chem. 2012, 22, 7845-7850. [CrossRef]

13. Wang, B.; Cheng, J.L.; Wu, Y.P.; Wang, D.; He, D.N. Porous NiO fibers prepared by electrospinning as high performance anode materials for lithium-ion batteries. Electrochem. Commun. 2012, 23, 5-8. [CrossRef]

14. Mohapatra, S.; Nair, S.V.; Santhanagopalan, D.; Rai, A.K. Nanoplate and mulberry-like porous shape of CuO as anode materials for secondary lithium-ion battery. Electrochim. Acta 2016, 206, 217-225. [CrossRef]

15. Xu, L.L.; Bian, S.W.; Song, K.L. Graphene sheets decorated with $\mathrm{ZnO}$ nanoparticles as anode materials for lithium-ion batteries. J. Mater. Sci. 2016, 49, 6217-6224. [CrossRef]

16. Kim, C.; Kim, J.W.; Kim, H.; Kim, D.H.; Choi, C.; Jung, Y.S.; Park, J. Graphene oxide assisted synthesis of self-assembled zinc oxide for lithium-ion battery anode. Chem. Mater. 2016, 28, 8498-8503. [CrossRef]

17. Zhang, Y.G.; Wei, Y.Q.; Li, H.P.; Zhao, Y.; Yin, F.X.; Wang, X. Simple fabrication of free-standing $\mathrm{ZnO} /$ graphene/carbon nanotube composite anode for lithium-ion batteries. Mater. Lett. 2016, 184, $235-238$. [CrossRef]

18. Yuan, G.; Wang, G.; Wang, H.; Bai, J. Synthesis and electrochemical investigation of radial ZnO microparticles as anode materials for lithium-ion batteries. Ionics 2015, 21, 365-371. [CrossRef]

19. Quartarone, E.; Dall'Asta, V.; Resmini, A.; Tealdi, C.; Tredici, I.G.; Tamburini, U.A.; Mustarelli, P. Graphite-coated $\mathrm{ZnO}$ nanosheets as high-capacity, highly stable, and binder-free anodes for lithium-ion batteries. J. Power Sources 2016, 320, 314-321. [CrossRef]

20. Huang, L.Y.; Wang, X.; Yin, F.X.; Zhang, Y.G.; Gao, J.W.; Liu, J.M.; Zhou, G.F.; Bakenov, Z. ZnO nanorods grown directly on copper foil substrate as a binder-free anode for high performance lithium-ion batteries. Int. J. Electrochem. Sci. 2016, 11, 8439-8446. [CrossRef]

21. Sun, F.; Gao, J.; Wu, H.; Liu, X.; Wang, L.; Pi, X.; Lu, Y. Confined growth of small ZnO nanoparticles in a nitrogen-rich carbon framework: Advanced anodes for long-life Li-ion batteries. Carbon 2017, 113, 46-54. [CrossRef]

22. Ahmad, M.; Yingying, S.; Sun, H.; Shen, W.; Zhu, J. SnO $2 / \mathrm{ZnO}$ composite structure for the lithium-ion battery electrode. J. Solid State Chem. 2012, 196, 326-331. [CrossRef]

23. Liu, Y.Z.; Li, Y.F.; Yang, Y.G.; Wen, Y.F.; Wang, M.Z. A one-pot method for producing ZnO-graphene nanocomposites from graphene oxide for supercapacitors. Scr. Mater. 2013, 68, 301-304. [CrossRef]

24. Feng, Y.; Zou, R.; Xia, D.; Liu, L.; Wang, X. Tailoring CoO-ZnO nanorod and nanotube arrays for Li-ion battery anode materials. J. Mater. Chem. A 2013, 1, 9654-9658. [CrossRef]

25. Shen, X.; Mu, D.; Chen, S.; Wu, B.; Wu, F. Enhanced electrochemical performance of ZnO-loaded/porous carbon composite as anode materials for lithium-ion batteries. ACS Appl. Mater. Interfaces 2013, 5, 3118-3125. [CrossRef] [PubMed]

26. Song, Y.; Chen, Y.; Wu, J.; Fu, Y.; Zhou, R.; Chen, S.; Wang, L. Hollow metal organic frameworks-derived porous $\mathrm{ZnO} / \mathrm{C}$ nanocages as anode materials for lithium-ion batteries. J. Alloy. Compd. 2017, 694, 1246-1253. [CrossRef] 
27. Mohanta, A.; Lanfant, B.; Asfaha, M.; Leparoux, M. Methane dissociation process in inductively coupled $\mathrm{Ar} / \mathrm{H}_{2} / \mathrm{CH}_{4}$ plasma for graphene nano-flakes production. Appl. Phys. Lett. 2017, 110, 093109. [CrossRef]

28. Hsieh, C.T.; Lin, C.Y.; Chen, Y.F.; Lin, J.S. Synthesis of ZnO@graphene composites as anode materials for lithium-ion batteries. Electrochim. Acta 2013, 111, 359-365. [CrossRef]

29. Guo, R.; Yue, W.; An, Y.; Ren, Y.; Yan, X. Graphene-encapsulated porous carbon-ZnO composites as high-performance anode materials for Li-ion batteries. Electrochim. Acta 2014, 135, 161-167. [CrossRef]

30. Li, S.; Xiao, Y.; Wang, X.; Cao, M. A ZnO-graphene hybrid with remarkably enhanced lithium storage capability. Phys. Chem. Chem. Phys. 2014, 16, 25846-25853. [CrossRef] [PubMed]

31. Fang, L.; Zhang, B.; Li, W.; Zhang, J.; Huang, K.; Zhang, Q. Fabrication of highly dispersed ZnO nanoparticles embedded in graphene nanosheets for high performance supercapacitors. Electrochim. Acta 2014, 148, 164-169. [CrossRef]

32. Zhao, Y.; Li, H.; Zhang, Y.; Xie, H.; Yin, F. One-pot Synthesis of radial ZnO microparticles deposited on graphene nanosheets as the anode materials for lithium-ion batteries. Int. J. Electrochem. Sci. 2016, 11, 3179-3189. [CrossRef]

33. Yang, S.; Song, X.; Zhang, P.; Gao, L. Facile synthesis of nitrogen-doped graphene-ultrathin $\mathrm{MnO}_{2}$ Sheet composites and their electrochemical performances. ACS Appl. Mater. Interfaces 2013, 5, 3317-3322. [CrossRef] [PubMed]

34. Zhao, P.; Li, W.; Wang, G.; Yu, B.; Li, X.; Bai, J.; Ren, Z. Facile hydrothermal fabrication of nitrogen-doped graphene $/ \mathrm{Fe}_{2} \mathrm{O}_{3}$ composites as high performance electrode materials for supercapacitor. J. Alloy. Compd. 2014, 604, 87-93. [CrossRef]

35. Gu, X.; Wu, F.; Lei, B.; Wang, J.; Chen, Z.; Xie, K.; Song, Y.; Sun, D.; Sun, L.; Zhou, H.; et al. Three-dimensional nitrogen-doped graphene frameworks anchored with bamboo-like tungsten oxide nanorods as high performance anode materials for lithium-ion batteries. J. Power Sources 2016, 320, 231-238. [CrossRef]

36. Peng, Y.G.; Ji, J.L.; Chen, D.J. Ultrasound assisted synthesis of $\mathrm{ZnO} /$ reduced graphene oxide composites with enhanced photocatalytic activity and antiphotocorrosion. Appl. Surf. Sci. 2015, 356, 762-768. [CrossRef]

37. Lin, Z.; Song, M.K.; Ding, Y.; Liu, Y.; Liu, M.; Wong, C.P. Facile preparation of nitrogen-doped graphene as a metal-free catalyst for oxygen reduction reaction. Phys. Chem. Chem. Phys. 2012, 14, 3381-3387. [CrossRef] [PubMed]

38. Tan, Y.; Zhu, K.; Li, D.; Bai, F.; Wei, Y.; Zhang, P. N-doped graphene/Fe-Fe3C nano-composite synthesized by a Fe-based metal organic framework and its anode performance in lithium-ion batteries. Chem. Eng. J. 2014, 258, 93-100. [CrossRef]

39. Xing, Z.; Ju, Z.; Zhao, Y.; Wan, J.; Zhu, Y.; Qiang, Y.; Qian, Y. One-pot hydrothermal synthesis of Nitrogen-doped graphene as highperformance anode materials for lithium-ion batteries. Sci. Rep. 2016, 6, 26146. [CrossRef] [PubMed]

40. Aurbach, D. Electrode-solution interactions in Li-ion batteries: A short summary and new insights. J. Power Sources 2003, 119, 497-503. [CrossRef]

41. Offeman, R.; Hummers, W. Preparation of graphitic oxide. J. Am. Chem. Soc. 1958, 80, 1339.

(C) 2018 by the authors. Licensee MDPI, Basel, Switzerland. This article is an open access article distributed under the terms and conditions of the Creative Commons Attribution (CC BY) license (http:/ / creativecommons.org/licenses/by/4.0/). 